\title{
EDITORIAL
}

\section{GEOSCIENCE CANADA - Changes and Challenges}

My term as Scientific Editor at Geoscience Canada began a couple of years ago, and I had every intention to place an editorial in the first issue of each year. Such intentions fell by the wayside, but changes over the last year and challenges that lie ahead prompt me to do so for the final issue of 2017. The last two years have been truly interesting, and I hope that the contents of volumes 43 and 44 indicate that the results of our collective efforts have proved worthwhile. I have elected to remain as editor for at least another year, so I think it is clear that the journey has, on the whole, proved positive.

My first task is to give thanks to everyone who makes Geoscience Canada possible four times a year. The greatest debt is of course to the authors of our papers, as without them the journal would not exist. It is our ambition to be the first choice of Canadian geoscientists for publication of ideas and research, but we recognize that this may not always be the case. Nevertheless, we continue to work towards that goal. If it were left to me, the demanding work of assembling each issue would be our greatest challenge, but luckily that task remains in far more capable hands. Our managing editor, Cindy Murphy, does a remarkable job, and handles the critical task of communicating with authors as their work moves through the publication pipeline. That pipeline has many sharp bends and constrictions, all of which have to be cleared, and I also must acknowledge the efforts of volunteer copy editors, who have improved the clarity and readability of papers over the last two years. One of our longest-serving copy editors, Reg Wilson of the New Brunswick Department of Natural Resources, stepped down from this role with his retirement this year, and I would like to thank him for his tireless and patient efforts. Anyone who has undertaken copy-editing work will know that it can test patience and resolve, and Reg had plenty of both. At one time, he was also the editor of Geoscience Canada, which certainly affirms this conclusion. Many of the papers that form part of thematic series contributions are handled by series editors, who solicit the papers, coordinate reviews, and shepherd them through revision and finalization. They are also a vital asset to the journal, and some have been with us for many years. One of those is Roger Macqueen, formerly of the Geological Survey of Canada in Calgary, who for many years has fronted our "Geology and Wine" series; Roger was also at one time the editor of Geoscience Canada. Although he retired from GSC sev- eral years ago, Roger continued his work with us, and only elected to retire from this task in 2017. We wish Reg and Roger all the best in their retirement, and thank them for their many and varied contributions. Followers of "Geology and Wine" need not despair, for we will continue the series, and anticipate a new paper on the terroir of Brazil in early 2018.

These are just a few of the many changes over the last two years. In 2015, Geoscience Canada became a hybrid open-access journal, and now, as a part of the Erudit consortium, we are further reducing the time period for which articles are available only by subscription to a mere 12 months. This is part of a wider policy shift on the part of Erudit, it remains to be seen what other challenges this transition might provide, but there is no doubt that making good geoscience freely available remains a key goal for us, and for GAC as a whole. We also developed a standalone website at wmm.geosciencecanada.ca that provides information about the journal and information for authors, and acts as a shell around the main journal management site hosted at the University of New Brunswick. As editor, I would be the first to admit that the new website still needs some work, and could in places be a much slicker operation, but this is one thing we can add to the 'challenge list' for 2018. Looking back at the papers from the last two years, they encompass a wide variety of topics, and fit with our general goal of diversifying across the broad spectrum of geoscience. As with everything else, there remains some distance yet to travel along this road. In addition to review papers and science contributions, Geoscience Canada also promotes geoscience outreach, and also provides a forum for discussion of issues in Canadian geoscience. Graham Young's thoughtful and entertaining presidential address (in this issue) provides valuable perspectives on outreach, based on many years of practical experience. This issue - and some issues to come in 2018 - will contain a series of articles connected to Professional Geoscience Registration issues in Canada and elsewhere. Although GAC itself is not in the business of professional licensure, it increasingly affects many of our members, and opinions on the subject are very diverse within our community. The subject is intrinsically a matter of perspective and policy rather than one of science alone, and we welcome the thoughts and contributions of readers who may wish to discuss ideas and opinions in these articles.

We are not lacking for challenges in the year to come, and my word limit simply will not allow all to be addressed. At the top of the list, and forever in our minds, is the task of attracting new paper submissions. Soliciting contributions, and then 
encouraging their completion once actually solicited, is one of my main tasks as editor. It is a bit like fishing - you need to know where to cast a line, and once you get a bite, you will often have a catch that tries desperately to wriggle off the hook. And not every catch makes it successfully into the editor's basket. Above all else, we are in need of quality submissions from committed authors. Once a paper makes it through peer review, we will do everything possible to move it along swiftly and smoothly, but we have to have the paper in the first place! So, if you have a topic in mind, please keep us in mind we are always open and eager for your business. Another challenge that we will face in 2018 is to review our 'thematic series' concepts, in order to focus on those that are most active, and to identify and initiate new concepts that we hope will attract future contributions. This will inevitably mean that some inactive thematic series may draw to a close, but papers related to those topics will still be welcome as general submission articles for our pages. We are also keen to hear ideas from readers about new thematic series concepts, and always keen to add new section editors to our roster as these ideas evolve.
In conclusion, Geoscience Canada is an important part of the Geological Association of Canada, and publishing technical information connected to geoscience is a key mandate for all of us. We could play an even larger role for GAC but, as always, we are constrained by limited resources and the fact that much of this effort is necessarily conducted by busy volunteers. Despite these challenges, we look forward to another year of increasingly diverse and hopefully more numerous articles in our pages, and continue to count on the interest and assistance of our readership in reaching these goals. We need volunteers to be copy-editors, and new ideas from new series editors, and we always will need new readers and subscribers. Please publicize the journal to colleagues within and outside GAC, use the contents of the journal in research, outreach, and also as an educational resource for students. And, above all, consider contributing to the journal by writing us a paper, or encouraging someone else to write one!

Andrew Kerr

Memorial University

St. John's, Newfoundland and Labrador

Canada, A1B $3 \times 5$

akern@mun.ca

\section{GEOLOGICAL ASSOCIATION OF CANADA} (2017-2018)

\section{OFFICERS}

\section{President}

Stephen Morison

Vice-President

Dène Tarkyth

\section{Past President}

Graham Young

Secretary-Treasurer James Conliffe

\section{OfFICERS \& COUNCILlors}

\section{COUNCILLORS}

Ihsan Al-Aasm

Alwynne Beaudoin

James Conliffe

Andy Kerr

Michael Michaud

Stephen Morison

David Pattison
Sally Pehrsson

Liz Stock

Dène Tarkyth

Deanne van Rooyen

Chris White

Graham Young

\section{STANDING COMMITTEES}

Communications: To be announced

Finance: Michael Michaud

GAC Lecture Tours: Alwynne Beaudoin

Publications: Chris White

Science Program: Deanne van Rooyen 